\title{
An Exploratory Study on the Consumers Use of Medicine in the State of Sarawak, Malaysia
}

\author{
Chuo Yew Ting ${ }^{1 *}$, Kah Seng Lee ${ }^{2 *}$, Robin Tiow-Heng Tan ${ }^{3}$, Wei Chern Ang ${ }^{2}$, Long Chiau Ming ${ }^{4,5}$ \\ ${ }^{1}$ Pharmaceutical Services Division, Sarawak State Health Department, MALAYSIA. \\ 2Pharmaceutical Services Division, Ministry of Health, MALAYSIA. \\ ${ }^{3}$ Pharmaceutical Services Division, Malacca State Health Department, MALAYSIA. \\ ${ }^{4}$ Vector-borne Diseases Research Group (VERDI), Pharmaceutical and Life Sciences CoRe, Universiti Teknologi MARA, Shah Alam, Selangor, MALAYSIA. \\ ${ }^{5}$ Faculty of Pharmacy, Universiti Teknologi MARA, Puncak Alam, Selangor, MALAYSIA.
}

\begin{abstract}
Introduction: The quality of a healthcare service relies on the rational use and the tight regulation of evidence-based medicine. By understanding how consumers take their medicines, policy makers were able to make appropriate intervention that caters for the practices and beliefs of the community. This cross-sectional survey study aimed to investigate the knowledge, awareness and behaviour of medicines usage by consumers in Sarawak. Method: A self-administered, paper-based validated questionnaire was distributed to the general public from $1^{\text {st }}$ September to $31^{\text {st }}$ October 2013. A proportionate cluster sampling was conducted, followed by stratified sampling to ensure similar sample size between urban and rural areas. Chi-square test was used to identify any statistically significant differences between urban and rural participants with their preference. Results and Discussion: $A$ total of 442 respondents were recruited where more respondents from rural area $(253,57.2 \%)$ were recruited. More than half of the respondents from both urban and rural groups respectively took some forms of medicines (urban: $111,58.7 \%$; rural: $156 ; 65.6 \%$ ), mostly on health supplements (urban: $48,25.4 \%$; rural: $61,24.1 \%$ ). In terms of the place to obtain their medicines, the Sarawak consumers preferred local
\end{abstract}

government hospital or clinic with $128(67.7 \%)$ among urban group and 221 $(87.4 \%)$ among rural groups. Only half of the respondents in urban group $(50.3 \%)$ were aware of "Know Your Medicine" campaign and $63.6 \%$ in rural group ( $p<0.05$ ). Conclusion: The knowledge of respondents towards the correct use of medicines was still considered unsatisfactory.

Correspondence :

Kah Seng Lee, BPharm (Hons), MBA, MPhil

Pharmaceutical Services Division, Ministry of Health, Lot 36, Jalan Universiti, 46350 Petaling Jaya, Selangor, MALAYSIA.

Phone no: +60 3-7841 3200

E-mail: kslee81@moh.gov.my

Chuo Yew Ting, BPharm (Hons), MPA

Pharmaceutical Services Division, Sarawak State Health Department, Jalan Diplomatik Off Jalan Bako, 93050 Petra Jaya, Kuching, Sarawak, MALAYSIA

Phone no: $+6082-473200$

DOI: $10.5530 / j y p .2016 .4 .26$

\section{INTRODUCTION}

Globally, medicines expenditure constitutes a large portion in the overall government expenditure. ${ }^{1,2}$ In Malaysia, the total expenditure of medical goods dispensed to patients under the Ministry of Health, which includes medicines has been on increasing trend, increasing from MYR 2,241 million in 2003 to MYR 6,846 million in 2012 (as of 20 September 2015, $1 \mathrm{MYR}$ was estimated to 0.24 USD). ${ }^{3}$ This represents an increase of two fold in the span of 10 years. The medical goods expenditure accounted for $16 \%$ of the total health expenditure in 2012 for Malaysia. ${ }^{3}$ Similarly, in 2011, the spending of medicines across OECD countries represents $17 \%$ of the total health expenditure. ${ }^{4}$ In view of the large amount of money spent on medicines, it is imperative for policy makers to understand why and how consumers make their choices in taking their medicines. The understanding of consumers' use of medicines will provide vital information for policy makers in developing interventions for rational use of medicines. ${ }^{5}$ For example, consumers in different geographical settings use medicines differently due to the variation in the demographic and social economic status, differences in the resources allocation and the disparities in healthcare workforce supply. ${ }^{6,7}$ Keyes et al. study observed significant differences in the use of nonmedical prescription opioid between the urban and rural population. ${ }^{8}$ In addition, Zhang et al. found differences in healthcare service utilization between rural and urban women. ${ }^{9}$ Malaysian consumers especially in the State of Sarawak being the largest state in Malaysia, is unique and diverse with many ethnicities and aboriginal ethnic groups. Some of the 40 ethnics present in Sarawak are unique to the state, thus presenting a suitable ground to study the use of medicine in a large variety of races and ethnicities. Communities from different ethnic groups have different beliefs, practices and needs and thus, use medicines differently. However, to date there are no studies available on the consumer use of medicines in State of Sarawak and limited studies in Malaysia generally.

In order to promote the rational use of medicines, the Ministry of Health Malaysia with the cooperation of the Federation of Consumers Association of Malaysia (FOMCA) launched a "Know Your Medicine" campaign in June $2007 . .^{10}$ This campaign aims to increase consumer awareness on rational use of medicines and their right to information on medicine. Workshops were conducted throughout the country for consumers targeting both rural and urban areas to ensure the messages reached the consumers. In addition to the campaign publicity in the mass media, quiz competitions for secondary schools, colleges and universities were organized. As a result of this campaign, a website (http://www.knowyourmedicine.gov.my) was launched to provide information to the public. The website provides consumers with educational materials and latest information on the campaign. Therefore, the objective of this study is to investigate the knowledge, awareness and behaviour of medicines usage by consumers in the state of Sarawak, Malaysia and also awareness of "Know Your Medicine" campaigns.

\section{METHODS}

This cross sectional survey study was aimed to investigate the knowledge, awareness and behaviour of medicines usage by consumers in Sarawak through administration of self-developed validated questionnaires to selected respondents in Sarawak from $1^{\text {st }}$ September 2013 to $31^{\text {st }}$ October 2013. By using Raosoft sample size calculator (Raosoft, Inc., Seattle, WA) with $95 \%$ confidence level, $5 \%$ margin of error and population size of 
$2,506,500,{ }^{11}$ a minimum of 385 samples were required in order to generalize the results to the studied population. By assuming there would be $10 \%$ of dropout rate, a minimum of 424 samples were required.

Multiple stage sampling was adopted in this study. A proportionate cluster sampling was conducted among the district of Kuching, Miri, Sibu and Bintulu and followed by stratified sampling to ensure similar sample size between urban and rural areas. The definition of 'rural' and 'urban' are based according to the National Survey on the Use of Medicines (NSUM) study. ${ }^{12}$ NSUM study defined "rural" as areas which have residents less than 10,000 or area which does not have local council while defined "urban" as otherwise. Respondents eligible for this study were 18 years old and above; were able to read and understood questionnaires either in English or Malay language.

Questionnaires in English and Malay languages were developed and reviewed through a panel of experts from the Sarawak Pharmacy Enforcement Branch. Face and content validation was done by three senior researchers in pharmacy practice. The questionnaire was pre-tested twice on a convenient sample of 35 general public (not included in final sample) frequenting a shopping centre. The reliability for the 29 items was established at .086 using the Cronbach-alpha, indicating good internal consistency. The questionnaires consist of five sections [total 29 items]: (1) demographic data[7 items], (2) pattern of medicine use [3 items], (3) access to medicine [2 items], (4) knowledge on the use of medicines [13 items] and (5) awareness on "Know Your Medicine" campaign [4 items]. Ethical approval was obtained from Medical Research and Ethics Committee (MREC), Ministry of Health Malaysia prior to the study. Paper-based questionnaires were distributed to the general public by data collectors. Prior to answering the survey, written informed consent was obtained from the respondents. The questionnaire was self-administered by the respondent. The data collectors ensured all the questions were answered upon the return of the questionnaires from the respondents.

Descriptive statistics was generated to provide frequency and percentage of occurrence. Chi-square test was used to identify any statistically significant differences between urban and rural participants with their preferences.

\section{RESULTS}

A total of 442 respondents participated in the survey where more respondents from rural area $(253,57.2 \%)$ were recruited. A great number of respondents (41.1\%) from rural area were found facing the problem of poverty as their monthly income was below MYR $1000(\approx$ USD 236.60). The respondents' demographic was summarized in Table 1 and generally represented the demographics of the state of Sarawak.

From Table 2, more than half of the respondents in urban group (59.3\%) and rural group (65.6\%) were taking certain forms of medicines during the period of study. Both groups of respondents mostly took health supplements (49.5\%), followed by controlled medicines for chronic diseases (17.3\%) and lastly non-process herbs (4.5\%). In Malaysian, controlled medicine is defined as prescription-only medicine, a substance listed under the scheduled poisons in First Schedule of Poison Act 1952.

Table 3 shows that majority of respondents from both groups preferred to consult government doctors in public sector as their initial course of action when experiencing health problems. However, more respondents from urban area (31.2\%) chose to consult private doctors compared to those from rural area (13.0\%).

In terms of the places to obtain their medicines, urban respondents were accustomed to government health facilities $(67.7 \%)$, followed by pharmacy outlet (67.2\%) and private health facilities (58.7\%). For urban respondents, there was no huge difference between preferences towards government health facilities and pharmacy outlets. However, for rural respondents, most of them preferred government health facilities (87.4\%) as compared to pharmacy outlet $(54.2 \%)$ and private health facilities (50.6\%). In total, both urban and rural area preferred private hospitals, followed by pharmacy outlets and private hospitals or clinics. The higher percentages of urban respondents going to pharmacy outlets than rural respondents shows urban respondents were more confidence in self-medication of minor health problems.

Table 4 shows that more than half of the respondents from urban area reported that they were aware of modern drug-traditional drug interaction $(64.4 \%)$, side-effects of medicines (64.9\%), drug-food interaction $(67.6 \%)$ and sharing of medication (29.8\%). On the other hand, majority of rural respondents also reported that they were aware of modern drugtraditional drug interaction (67.6\%), side-effects of medicines (67.0\%), drug-food interaction $(74.1 \%)$ and sharing of medication $(25.4 \%)$. In addition, there was no significant difference between urban and rural respondents in terms of the awareness towards medication safety.

Approximately $58 \%$ of urban and rural respondents were able to differentiate between generic name and brand name of a medicine. Interestingly, there was no significant difference between both groups.

The practice of storing medicines at places protected from sunlight/heat was reported by $93.1 \%$ of urban respondents and $89.9 \%$ of rural respondents respectively (Table 5).

Approximately $85 \%$ of respondents from both groups knew that medicines and health supplements need to be registered with the Drug Control Authority, Ministry of Health $(\mathrm{MOH})$. However, urban respondents were significantly having higher knowledge on the criteria of a registered product as compared to rural respondents $(\mathrm{p}<0.05)$.

The result shows approximately half of the respondents in urban group (50.3\%) was aware of the "Know Your Medicine" campaign while 63.6\% respondents in rural group were significantly more aware of this campaign $(\mathrm{p}<0.05)$. In term of attendance to exhibitions or talks on medicines, less than $45 \%$ of respondents in both urban and rural groups had ever attended while only $25 \%$ of respondents from both groups had participated in the "Know Your Medicine" campaign.

\section{DISCUSSIONS}

In general, most respondents took health supplements (49.5\%), followed by controlled medicines for chronic diseases (17.3\%) and lastly nonprocess herbs $(4.5 \%)$. This finding were lower than a local nationwide survey previously done, which the findings were reported to be $62.3 \%$, $28.4 \%$ and $9.6 \%$ respectively. This simply shows that a smaller portion of Sarawakians was taking controlled medicines, health supplements and non-process herbs as compared to whole Malaysia population. ${ }^{13}$

In Malaysia, the healthcare system comprises of tax-funded and government-run primary healthcare institutions and private healthcare facilities which rely on the publics' out-of-pocket expenditure. ${ }^{14}$ Thus, it was not unusual for Sarawakians to consult doctors in public health facilities as their initial course of action and to obtain their medicine when experiencing health problems due to economic concerns.

Through a semi-structured interviews exploring consumer health information-seeking behaviours of a local Korean community in Tallahassee, Florida, ${ }^{15}$ health services provided by authoritative health facilities had cognitive authority, which was influenced by their performance. Interviewees were more attentive to health information delivered by health care professionals who were knowledgeable in a health care field. ${ }^{15}$ In terms of medicine, pharmacists must be knowledgeable in the medicine that they dispensed to the patients to gain trust from the patients. Experiential knowledge and applicability were likely to be considered by ethnic minorities. ${ }^{16}$ Pharmacists must be aware of side effects or even 
Table 1: Demographics of the respondents

\begin{tabular}{|c|c|c|}
\hline \multirow[t]{2}{*}{ Characteristics } & \multicolumn{2}{|c|}{ Frequency (\%) } \\
\hline & Urban Area & Rural Area \\
\hline Respondent recruited & $189(42.8)$ & $253(57.2)$ \\
\hline \multicolumn{3}{|l|}{ Gender } \\
\hline Male & $77(40.7)$ & $105(41.5)$ \\
\hline Female & $110(58.2)$ & $148(58.5)$ \\
\hline \multicolumn{3}{|l|}{ Age } \\
\hline 18- 24 years old & $31(16.4)$ & $40(15.8)$ \\
\hline 25- 34 years old & $76(40.2)$ & $67(26.5)$ \\
\hline 35- 44 years old & $45(23.8)$ & $74(29.2)$ \\
\hline 45- 54 years old & $19(10.1)$ & $49(19.4)$ \\
\hline $55-64$ years old & $12(06.3)$ & $18(07.1)$ \\
\hline$\geq 65$ years old & $4(02.1)$ & $5(02.0)$ \\
\hline \multicolumn{3}{|l|}{ Ethnicity } \\
\hline Malay & $90(47.6)$ & $119(47.0)$ \\
\hline Chinese & $50(26.5)$ & $41(16.2)$ \\
\hline Non-Malay natives & $44(23.3)$ & $92(36.4)$ \\
\hline Indian & $1(00.5)$ & $1(00.4)$ \\
\hline \multicolumn{3}{|l|}{ Occupation } \\
\hline Government servant & $72(38.1)$ & $114(45.1)$ \\
\hline Self-employment & $68(36.0)$ & $73(28.9)$ \\
\hline Retired & $4(02.1)$ & $3(01.2)$ \\
\hline Student & $12(06.3)$ & $8(03.2)$ \\
\hline Unemployed & $31(16.4)$ & $55(21.7)$ \\
\hline \multicolumn{3}{|l|}{ Monthly Income } \\
\hline MYR 0- RM 1,000 & $45(23.8)$ & $104(41.1)$ \\
\hline MYR 1,001- RM 2,000 & $39(20.6)$ & $63(24.9)$ \\
\hline MYR 2,001- RM 3,000 & $45(23.8)$ & $22(08.7)$ \\
\hline MYR 3,001- RM 5,000 & $39(20.6)$ & $39(15.4)$ \\
\hline$>$ MYR 5,000 & $14(07.4)$ & $25(09.9)$ \\
\hline \multicolumn{3}{|l|}{ Highest education level } \\
\hline Primary & $12(06.3)$ & $36(14.2)$ \\
\hline Secondary & $90(47.6)$ & $143(56.5)$ \\
\hline College/University & $82(43.4)$ & $64(25.3)$ \\
\hline No formal education & $4(02.1)$ & $10(04.0)$ \\
\hline \multicolumn{3}{|l|}{ Living Status } \\
\hline Alone & $35(18.5)$ & $38(15.0)$ \\
\hline With family & $153(81.0)$ & $209(82.6)$ \\
\hline
\end{tabular}

\section{Table 2: Pattern of Medicines Use}

\begin{tabular}{lcc}
\hline \multirow{2}{*}{ The preparations that I take currently } & \multicolumn{2}{c}{ Frequency (\%) } \\
\cline { 2 - 3 } & Urban Area & Rural Area \\
\hline (A) Controlled medicine for chronic diseases & $14(7.4)$ & $25(9.9)$ \\
(B) Health supplement products & $48(25.4)$ & $61(24.1)$ \\
$(C)$ Non-processed herbs & $4(2.1)$ & $6(2.4)$ \\
$(D)$ None & $77(40.7)$ & $87(34.4)$ \\
$($ E) $=(A)+(B)+(C)$ & $13(6.9)$ & $19(7.5)$ \\
$(F)=(A)+(B)$ & $14(7.4)$ & $34(13.4)$ \\
$(G)=(B)+(C)$ & $13(6.9)$ & $19(7.5)$ \\
$(H)=(A)+(C)$ & $5(2.6)$ & $2(0.8)$ \\
\hline
\end{tabular}




\section{Table 3: Access to Medicine}

\begin{tabular}{lcc}
\hline & \multicolumn{2}{c}{ Frequency (\%) } \\
\cline { 2 - 3 } & Urban Area & Rural Area \\
\hline 1) If I were experiencing any health problems, the first action that I would take & & \\
a) Consult government doctor & $91(48.1)$ & $200(79.1)$ \\
b) Consult private doctor & $59(31.2)$ & $33(13.0)$ \\
c) Consult pharmacist in pharmacy outlet & $15(07.9)$ & $5(02.0)$ \\
d) Consult traditional practitioner & $1(00.5)$ & $1(00.4)$ \\
e) Self-medication & $22(11.6)$ & $13(05.1)$ \\
2) The places that I usually obtain my medicine (may choose more than 1) & & \\
a) Government hospital or clinic & $128(67.7)$ & $221(87.4)$ \\
b) Private hospital or clinic & $111(58.7)$ & $128(50.6)$ \\
c) Pharmacy outlet & $127(67.2)$ & $137(54.2)$ \\
d) Traditional drug store & $14(07.4)$ & $16(06.3)$ \\
e) Grocery shop & $19(10.1)$ & $20(07.9)$ \\
f) Morning market/ night market & $4(02.1)$ & $3(01.2)$ \\
\hline
\end{tabular}

Table 4: Awareness on medication safety (side effects, drug interaction and sharing of medication)

\begin{tabular}{|c|c|c|c|c|c|c|c|}
\hline \multirow{2}{*}{\multicolumn{2}{|c|}{ Questions }} & \multicolumn{2}{|c|}{ Urban } & \multicolumn{2}{|c|}{ Rural } & \multirow[b]{2}{*}{$x^{2}$} & \multirow[b]{2}{*}{$p$-valuea } \\
\hline & & $\begin{array}{c}\text { Yes } \\
\mathrm{n}(\%)\end{array}$ & $\begin{array}{c}\text { No } \\
n(\%)\end{array}$ & $\begin{array}{c}\text { Yes } \\
\mathrm{n}(\%)\end{array}$ & $\begin{array}{c}\text { No } \\
n(\%)\end{array}$ & & \\
\hline & $\begin{array}{l}\text { Are you aware that there are some of modern and traditional medicine } \\
\text { should not to be taken together? }\end{array}$ & $121(64.4)$ & $67(35.6)$ & $125(67.6)$ & $60(32.4)$ & 0.427 & 0.514 \\
\hline 2) & Are you aware of the side effects of your medicines? & $122(64.9)$ & $66(35.1)$ & $124(67.0)$ & $61(33.0)$ & 0.189 & 0.664 \\
\hline 3) & $\begin{array}{l}\text { Are you aware that there is medicine/food that should not been taken } \\
\text { together? }\end{array}$ & $127(67.6)$ & $61(32.4)$ & $137(74.1)$ & $48(25.9)$ & 1.905 & 0.167 \\
\hline 4) & Have you ever shared any medicine with others? & $56(29.8)$ & $132(70.2)$ & $47(25.4)$ & $138(74.6)$ & 0.896 & 0.344 \\
\hline
\end{tabular}

a Chi-square test for independence, ${ }^{*}$ significant at $\mathrm{p}<0.05$.

Table 5: Practice on medication storage and disposal

\begin{tabular}{l} 
Questions \\
\cline { 3 - 6 }
\end{tabular}

${ }^{a}$ Chi-square test for independence, ${ }^{*}$ significant at $p<0.05$. 
adverse drug reactions (ADRs) that were common in their community that served in, do the necessary reporting to Malaysian Adverse Drug Reactions Advisory Committee (MADRAC) for pharmacovigilance purposes and research in these fields in that community, as most 'theoretical' side effects in the literature are that of Caucasians or major Asian groups only. However, more respondents from urban area (31.2\%) choose to consult private doctors compared to those from rural area (13.0\%). This could be explained by the fact that most of the private healthcare facilities were located in urban areas and cater more on ambulatory care.

The present survey revealed the likelihood of self-medication practice in literate participants as compared to illiterate participants. Other studies in Nigeria showed the influence of education on self-medication practice. ${ }^{17,18}$ Educated patients are able to read and understand the labels of consumed medicines, while illiterate people find it almost impossible to read and understand the labels.

When it comes to the awareness on medication safety, majority ( $>60 \%)$ of the respondents reported that they were aware of modern drug-traditional drug interaction, side-effects of medicines, drug-food interaction and sharing of medication. These findings concurred with the finding of the national survey. ${ }^{19}$ Ironically, in a cross-sectional survey among elderly population aged 60 years and above, living in the urban state of Selangor and Federal Territory Kuala Lumpur, Malaysia, nearly half of the respondents ( $\mathrm{n}=123 ; 48 \%)$ admitted using complementary and alternative medicines (CAM) as they perceived that CAM is safer than allopathic medicine. Age $(\mathrm{p}=0.002)$ and ethnicity $(\mathrm{p}=0.001)$ showed statistical significance. Elderly aged 60-69 years old and of Chinese ethnicity had this strong misconception..$^{20}$ Efforts should be put forth by authorities in increasing the awareness about the possible drug interactions.

Approximately $58 \%$ of urban and rural Sarawak respondents were able to differentiate generic name from brand name of a medicine without significant differences between both groups. On the contrary, national survey revealed that urban respondents (54.5\%) were significantly more informed about the differences between generic and innovator drugs than rural respondents (37.7\%). ${ }^{19}$ On the other hand, approximately $85 \%$ of respondents from both groups were aware that medicines and health supplements need to be registered with the Drug Control Authority, Ministry of Health of Malaysia.

More than $89 \%$ of respondents were able to store their medicines in appropriate places but less than half of the urban and rural respondents returned the unwanted medicines to the pharmacy in nearby government hospital or clinics. In fact, most of them disposed unwantedmedicines into the garbage bin which is more convenient to do so. The inappropriate disposal of unwanted medicines had proved to cause pharmaceutical pollution to the environment and critical measures need to be taken by relevant authorities. ${ }^{21}$

When it comes to the low awareness $(<65 \%)$ about "Know Your Medicine" campaign and its unsatisfactory attendance $(<45 \%)$, the state Pharma- ceutical Services Division need to implement better strategies to effectively increase the awareness and involvement of the Sarawak population.

There were several limitations to this study. As this study was using selfadministered questionnaire, respondents who are unable to read and understand questionnaire in Malay or English language had to be excluded even though they were chronic-medication users. 5-point Likert scale could be used as a better psychometric scale in employing the questionnaire instead of a dichotomous response in this questionnaire.In addition, data collectors were unable to reach respondents who reside in deep inner rural areas in Sarawak due to logistic problems, cost and time factors (as some villages in Sarawak were only accessible by boats). Thirdly, the evaluation of consumers' awareness was based on a self-reported assessment and hence the actual consumers' behaviour cannot be verified. Lastly, more sub-analysis with greater sample size can be done to explore the association between awareness on the quality use of medicines and demographic characteristics such as education level.

\section{CONCLUSION}

This study revealed the knowledge, awareness and behaviour of the consumers in Sarawak towards the use of medicines. Method of obtaining medicines by the Sarawak consumers was mainly through government hospitals or clinics. However, those in urban area had higher possibilities of going to private hospital or clinic for health consultation. To conclude, there are still a lot of rooms for improvement in creating awareness, widening the platforms of information dissemination and improving the understanding of the public in Sarawak towards the proper use of medicines. Future study using the same questionnaire should be carried out regularly in order to monitor the progress and to measure the effectiveness of health promotion programmes held by Sarawak Pharmacy Enforcement Branch.

\section{ACKNOWLEDGEMENT}

This work was supported by Pharmaceutical Services Division, Ministry of Health and Academic and Research Assimilation grants [600-RMI/ DANA 5/3/ARAS (46/2015)]. The authors would like to express their gratitude to Ministry of Health, Ministry of Higher Education and Universiti Teknologi MARA (UiTM), Malaysia for financial support for this research. The authors would like to thank the Director of Health Malaysia for permission to publish this paper. The funders had no role in study design, data collection and analysis, decision to publish, or preparation of the manuscript.

\section{CONFLICT OF INTERESTS}

The author declare no conflict of interest.

\section{ABBREVIATIONS USED}

MYR: Malaysian Ringgit; OECD: The Organisation for Economic Co-operation and Development; FOMCA: Federation of Consumers Association of Malaysia; NSUM: National Survey on the Use of Medicines; MREC: Medical Research and Ethics Committee; CAM: complementary and alternative medicines.

\section{ABOUT AUTHORS}

Kah Seng Lee: Obtained his MPhil degree in 2016 from Curtin University, Australia. Currently, he is the Senior Principal Assistant Director at the Pharmaceutical Services Division, Ministry of Health Malaysia. His research interests are in health system and policy implementations, pharmaceutical pricing and reimbursement policies. He is currently working on several projects in collaboration with national and international institutions in aspects regard to differential pricing in pharmaceutical market, pricing of high-cost medicines and price control policy. 


\section{REFERENCES}

1. Alrasheedy AA, Hassali MA, Aljadhey H, Ibrahim MIM, Al-Tamimi SK. Is there a need for a formulary of clinically interchangeable medicines to guide generic substitution in Saudi Arabia?. J Young Pharm. 2013;5(2):73-5.

2. Singh S, Gupta AK, Latika MD. ABC and VED analysis of the pharmacy store of a tertiary care, academic institute of the Northern India to identify the categories of drugs needing strict management control. J Young Pharm. 2015;7(2):77.

3. Malaysia National Health Accounts Unit. Malaysia National Health Accounts: Health Expenditure Report 1997-2012. Putrajaya, Malaysia: Ministry Health Malaysia;2013.

4. Organisation for Economic Co-operation and Development. Health at a Glance: Europe 2013. OECD Publishing;2013.

5. Sam AT, Parasuraman S. Assessment of pharmaceutical care services provided by a community pharmacy in Kedah, Malaysia. Pharmacol Toxicol Biomed Rep. 2015;1(2).73-80.

6. Manohar VS, Vinay M, Jayasree T, Kishan PV, Ubedulla S, Dixit R. Prescribing pattern of gastroprotective agents with non-steroidal anti-inflammatory drugs. J Pharmacol Pharmacother. 2013;4(1):59-60.

7. Singh J. Evaluation of the appropriateness of prescribing in geriatric patients using Beers' criteria and Phadke's criteria and comparison thereof by Rima Shah and colleagues. Journal of Pharmacology and Pharmacotherapeutics. 2012;3(1):81

8. Keyes KM, Cerdá M, Brady JE, Havens JR, Galea S. Understanding the RuralUrban Differences in Nonmedical Prescription Opioid Use and Abuse in the United States. Am J Public Health. 2014;104(2):e52-e59.

9. Zhang P, Too G, Irwin KL. Utilization of Preventive Medical Services in the United States: A Comparison Between Rural and Urban Populations. J Rural Health. 2000;16(4):349-56.

10. Pharmaceutical Services Division. Know Your Medicine. Available from: http:// www.knowyourmedicine.gov.my. Accessed 2 Jan 2016. 2015.

11. Department of Statistics (Malaysia). Sarawak at a glance. Available from: https://www.statistics.gov.my/index.php? $r=$ column/cone\&menu_id=clJnWTIT bWFHdmUwbmtSTE1EOStFZz09. Accessed 3 Jan 2016. 2015
12. Pharmaceutical Services Division. The National Survey on the Use of Medicines (NSUM). Ministry of Health Malaysia;2012.

13. Hassali MA, Shafie AA, Chua G. A National Survey On the Use of Medicines (NSUM). Available from: http://www.pharmacy.gov.my/v2/sites/default/files/ document-upload/book.national-survey-use-medicines-2.12.pdf. Accessed 3 Jan 2016. 2013.

14. Safurah J, Khairiyah A, Nour H, Healy J. Malaysia health system review. Health Systems in Transition. Geneva, Switzerland: World Health Organization. 2013.

15. Yong JY, Stvilia B, Mon L. Cultural influences on seeking quality health information: An exploratory study of the Korean community. Libr Inf Sci Res. 2012;34(1):45-51.

16. Nettleton S, Burrows R, O'Malley L. The mundane realities of the everyday lay use of the internet for health, and their consequences for media convergence. Sociol Health IIIn. 2005;27(7):972-92.

17. Afolabi AO. Factors influencing the pattern of self-medication in an adult Nigerian population. Ann Afr Med. 2008;7(3):120-7.

18. Osemene K, Lamikanra A. A study of the prevalence of self-medication practice among university students in Southwestern Nigeria. Trop J Pharm Res. 2012; 11(4):683-9.

19. Wong ZY, Hassali MA, Alrasheedy AA, Saleem F, Yahaya AH, Aljadhey $H$. Patients' beliefs about generic medicines in Malaysia. Pharm Pract (Granada). 2014;12(4):474.

20. Mitha S, Nagarajan V, Babar MG, Siddiqui MJA, Jamshed SQ. Reasons of using complementary and alternative medicines (CAM) among elderly Malaysians of Kuala Lumpur and Selangor states: An exploratory study. J Young Pharm. 2013;5(2):50-3.

21. Kotchen M, Kallaos J, Wheeler K, Wong C, Zahller M. Pharmaceuticals in wastewater: behavior, preferences, and willingness to pay for a disposal program. J Environ Manage. 2009;90(3):1476-82. 